\title{
Peg-interferon Plus Ribavirin Combination Therapy in HCV Mono-infected and HCV/HIV Co-infected Patients in Iran
}

\author{
Khashayar Hesamizadeh ${ }^{1}$, Ahmad Tavakoli², Mehri Nikbin*1,3 \\ Received: 18 May 2018 \\ Published: 1 Jul 2019
}

\begin{abstract}
Background: Hepatitis $\mathrm{C}$ virus (HCV) infection is a cause of major liver complications, particularly in patients infected with human immunodeficiency virus (HIV). This study aimed to evaluate the efficacy of pegylated interferon (Peg-IFN) and a fixed dose of ribavirin treatment among Iranian $\mathrm{HCV}$ mono-infected and $\mathrm{HCV} / \mathrm{HIV}$-co-infected patients.

Methods: A total of $214 \mathrm{HCV}$ mono-infected and HCV/HIV co-infected patients attending Liver Disease Center in Tehran were assigned to receive treatment with Peg-IFN- $\alpha 2 \mathrm{a}$ or $-\alpha 2 \mathrm{~b}$ plus ribavirin for $24-48$ weeks. Sustained virologic response (SVR) was used as the primary efficacy endpoint of Peg-IFN and ribavirin therapy.

Results: Treatment with Peg-IFN and ribavirin has been associated with a considerably higher rate of SVR ( 24 weeks for HCV genotype 3 and 48 weeks for HCV/HIV co-infected and HCV genotype 1 patients). Overall, the clearance of HCV-RNA at the end of therapy occurred in $48.6 \%$ of patients. Adverse events leading to treatment discontinuation were seen in $14 \%$ of patients.

Conclusion: This retrospective study revealed a relatively well-tolerated response in both $\mathrm{HCV}$ mono-infected and $\mathrm{HCV} / \mathrm{HIV}$ coinfected patients during treatment with Peg-IFN and ribavirin. However, the recent revolutionized interferon-free therapies for chronic HCV infection should be taken into account for achieving a greater response and minimal adverse events.
\end{abstract}

Keywords: Hepatitis C, HIV, Pegylated interferon, Ribavirin, Iran

Conflicts of Interest: None declared

Funding: Middle East Liver Disease (MELD) Center, Tehran, Iran

*This work has been published under CC BY-NC-SA 1.0 license

Copyright $($ Iran University of Medical Sciences

Cite this article as: Hesamizadeh Kh, Tavakoli A, Nikbin M. Peg-interferon Plus Ribavirin Combination Therapy in HCV Mono-infected and HCV/HIV Co-infected Patients in Iran. Med J Islam Repub Iran. 2019 (1 Jul);33:63. https://doi.org/10.47176/mjiri.33.63

\section{Introduction}

Hepatitis $\mathrm{C}$ is still a common life-threatening infectious diseases in global communities. It is estimated that 71 million individuals are living with chronic HCV infection globally with 1.75 million new infections emerging each year $(1,2)$. It turns out that, hepatitis $\mathrm{C}$ contributes to the advanced liver disease. According to the recent data, ap-
Corresponding author: Dr Mehri Nikbin, nikbin_mehri@yahoo.com

1. Middle East Liver Disease (MELD) Center, Tehran, Iran

2. Department of Medical Virology, Faculty of Medicine, Iran University of Medical Sciences, Tehran, Iran

3. Baqiyatallah Research Center for Gastroenterology and Liver Diseases (BRCGL), Baqiyatallah University of Medical Sciences, Tehran, Iran $\uparrow$ What is "already known" in this topic:

$\mathrm{HIV} / \mathrm{HCV}$ co-infected patients are reported to have increased rates of acute $\mathrm{HCV}$ infection which progress to chronicity, leading to the development of cirrhosis, hepatocellular carcinoma, and liver failure. Various studies have shown that combination therapy with Peg-IFN and ribavirin are associated with different sustained virologic responses (SVR) in these patients. The present study was performed to evaluate the efficacy of Peg-IFN and a fixed dose of ribavirin treatment among Iranian HCV mono-infected and HCV/HIV-co-infected patients.

\section{$\rightarrow$ What this article adds:}

The efficacy of 24-48 weeks regimens of Peg-IFN plus ribavirin represent proper results in our HCV infected patients. In total, $76 \%$ and $53 \%$ of $\mathrm{HCV}$ mono-infected and HCV/HIV co-infected patients achieved SVR, respectively. The present study as the first reports of the efficacy of Peg-IFN-alfa plus RBV among Iranian HCV/HIV coinfected patients revealed that the regimen is relatively well tolerated in the patient's group. 
proximately 480 thousand $\mathrm{HCV}$ infected-individuals are living in Iran (3). Although it is much lower than the statistics from countries neighboring Iran and also the other Eastern Mediterranean (EMRO) countries, the treatment of these patients is very pivotal for achieving the elimination strategy $(4,5)$.

Co-infection with human immunodeficiency virus (HIV) is a challenge in people living with HCV infection, given more rapid progression of HCV related liver fibrosis, increased mortality, lower rates of spontaneous $\mathrm{HCV}$ clearance in those with HIV-HCV co-infection $(6,7)$. All the evidence represent the group as a "special population". It is also estimated that nearly 2.3 million world people are living with HIV-HCV co-infection $(8,9)$.

Before the introduction of direct-acting antivirals (DAAs), standard regimen for the treatment of chronic HCV was Peg-IFN plus ribavirin in a 24-48 weeks course (10-12). Common adverse events of treatment, such as psychiatric disorders, anemia, and neutropenia were reported in patients receiving the regimens. Ribavirin may interfere with antiretroviral medications such as zidovudine and stavudine (13) and may reinforce the toxic effects of didanosine (14).

Combination of ribavirin and Peg-IFN provides different sustained virologic responses. It is affected by the baseline HCV RNA level, HCV genotypes and coinfection with HIV; $70-90 \%$ response for HCV genotype 2 and genotype 3 , almost $50 \%$ for HCV genotype 1 and genotype 4 in HCV mono-infected patients (15) and 50\% for $\mathrm{HCV}$ genotype 2 and 3 besides $21-32 \%$ for $\mathrm{HCV}$ genotype 1 and 4 in HCV/HIV co-infected patients (16).

The aim of our retrospective study is the initial treatment of chronic HCV in Iranian HCV mono-infected and $\mathrm{HCV} / \mathrm{HIV}$ co-infected patients to investigate the efficacy of a 24-48 week course of standard Peg-IFN alfa $2 \mathrm{a}$ and $2 \mathrm{~b}$ plus ribavirin.

\section{Methods \\ Study population}

Patients with chronic hepatitis C and HIV infection attended the Association of Liver Diseases in Tehran from September 2012 enrolled in this cross-sectional study. The exclusion criteria were: presence of $\mathrm{HBV} / \mathrm{HCV}$ coinfection, hepatocellular carcinoma (HCC), livertransplanted patients, malignant neoplasms, diabetic patients, psychiatric disorders, autoimmune disorders, $\beta$ thalassemia, creatinine clearance lower than 50 $\mathrm{mL} /$ minute, patients with severe decompensated chronic liver disease, chronic respiratory failure, severe cardiac disease, and active substance abuse. The study protocol was approved by the institutional ethics committee, and all procedures contributing to this work complied with the Declaration of Helsinki. Questionnaires were completed by participants, and the privacy for research participants was respected in this study.

\section{Laboratory methods}

Laboratory methods including serology for HCV antibody detection and confirmation by RIBA test, HCV and HIV viral loads and genotypes determination. HCV geno- typing was performed by a commercially available assay (InnoLiPA, Innogenetics, Ghent, Belgium). For determination of HIV viral loads, a COBAS TaqMan 48 Analyzer (Roche Diagnostics, Germany) was used, according to the manufacturer's protocol. Furthermore, the CD4 cells count was performed by means of flow cytometry technique in HIV-infected patients. Interleukin 28B genotyping was also performed using a TaqMan 5' allelic discrimination assay (Applied Biosystems, Foster City, CA).

A combination of pegylated interferon $a-2 a$ or $2 b$ and ribavirin was used for management of chronic HCV infection. The treatment response was evaluated based on HCV RNA levels. HCV RNA levels were analyzed using COBAS Taqman HCV Test (Roche Diagnostics, Germany) with a detection limit of $10 \mathrm{IU} / \mathrm{mL}$. SVR is defined as the absence of HCV RNA within 24 weeks after treatment completion. Relapse is also defined as the reappearance of HCV RNA within 24 weeks after treatment completion and before achieving the SVR. Withdrawal means the discontinuation of treatment before finishing the therapy, which may be owing to resistance, drugs adverse effects or even patient's poor cooperation. A decrease of less than 2 logs $10 \mathrm{IU} / \mathrm{mL}$ from baseline HCV RNA level at week 12 or a detectable HCV RNA level both at week 24 and after that, considered as resistance. HCV spontaneous clearance is the clearance of $\mathrm{HCV}$ infection within 6 months of exposure without any treatments. Approximately $25 \%$ of adults infected with hepatitis $\mathrm{C}$, spontaneously clear the virus without treatment, some studies have found various rates ranging from about $15 \%$ to $50 \%$ (17). Erythropoietin and granulocyte colony stimulating factor (GCSF) were applied if the patients' hemoglobin level or neutrophil counts decreased under $10 \mathrm{~g} / \mathrm{dL}$ or $500 / \mathrm{mL}$, respectively. Treatment response was evaluated according to an intention-to-treat analysis. The primary endpoint SVR was defined as undetectable HCV RNA in serum 2448 weeks after the end of treatment. Patients who did not exhibit significant decreases $(\geq 2$ logs) in HCV RNA levels were considered as non-responders.

\section{Treatment of Chronic HCV Infection}

In this study, weekly subcutaneous injection of $180 \mu \mathrm{g}$ of Pegaferon ${ }^{\circledR}$ (PegIFN-alpha-2a by Pooyesh Darou, Tehran, Iran) or $1.5 \mu \mathrm{g}$ per $\mathrm{kg}$ body weight of Pegintron $\AA$ (PegIFN-alpha-2b by Merck, USA) plus daily oral administration of Ribabiovir ${ }^{\circledR}$ (Ribavirin by Bakhtar Bioshimi, Kermanshah, Iran), was prescribed for 24-48 weeks in all $\mathrm{HCV}$ patients (HCV genotype 1 and 3 mono-infected and $\mathrm{HCV} / \mathrm{HIV}$ co-infected patients) regardless of baseline HCV RNA levels. The doses of RBV in all subjects were adjusted according to body weight (1000 - $1200 \mathrm{mg}$ based on body weight below or over $75 \mathrm{~kg}$ in genotype 1 and $800 \mathrm{mg}$ in genotype 3).

\section{Statistical analysis}

Data analysis was carried out using the SPSS 20.0. After descriptive analysis, comparison between groups was performed using univariate analysis. For comparing proportions, chi-square test or paired t-test was used. Finally, a multiple logistic regression analysis was used to exam- 
ine the effect of factors including HCV genotypes, liver functional tests, liver fibrosis and demographic features on treatment responses (SVR). P-values of less than 0.05 were considered to be statistically significant.

\section{Results}

\section{Baseline characteristics}

Out of 214 patients, 134 were HCV mono-infected, and 80 were HCV/HIV co-infected patients. Furthermore, $94 \%$ were male, and $6 \%$ were female (mean age 42 years old), and the majority of them were intravenous drug users. The main demographics and biological features of the study population are depicted in Table 1 . All of the HIV infected subjects were on highly active antiretroviral therapy (HAART). The distribution of participants in the study is shown in Figure 1.

Of note, $37.4 \%$ of patients had acquired HIV and HCV as co-infection, the majority by intravenous drug using. Based on the types of infection (HCV mono or HCV/HIV co-infection), patients divided into two groups: group 1 and group 2 including $\mathrm{HCV}$ mono and $\mathrm{HCV} / \mathrm{HIV}$ coinfected patients, respectively. About half of the patients were infected with HCV genotype 1 (1a and 1b), and 75 $(38 \%)$ of patients were infected with genotype 3 . No patients were infected with HCV genotype 2 and 4. Unfortunately, 34 patients were defined as non-type.

Results from a reliable liver biopsy were available for $126(58.8 \%)$ of 214 patients. Fibroscan data showed that $43 \%$ of patients were in advanced liver fibrosis (Metavir F3 and F4). The alleles of IL28 were also available for only 95 (44.4\%) patients, the majority of which have been CC and CT alleles, $50.5 \%$ and $43.2 \%$, respectively.

Furthermore, the decreasing hemoglobin under $10 \mathrm{mg} / \mathrm{dl}$ was observed in 154 patients (55\% in group 2 patients). Erythropoietin (EPREX 10.000 IU) was prescribed for 97

Table 1. Demographics and biological features of the study population

\begin{tabular}{|c|c|}
\hline Age & $1-65$ \\
\hline Mean Age $( \pm \mathrm{SD})$ & $42(10.2)$ \\
\hline \multicolumn{2}{|l|}{ Gender, $\mathrm{n}(\%)$} \\
\hline Male & $201(93.9)$ \\
\hline Female & $13(6.1)$ \\
\hline Platelets $<100 \times 10^{9} / \mathrm{L}$ & $22(10 \%)$ \\
\hline $\mathrm{AST}$, mean $( \pm \mathrm{SD})$ & $57( \pm 47)$ \\
\hline $\mathrm{ALT}$, mean $( \pm \mathrm{SD})$ & $73( \pm 63)$ \\
\hline Body-mass index $\left(\mathrm{kg} / \mathrm{m}^{2}\right)$ & $26.1( \pm 4.13)$ \\
\hline HIV patients & $80(37.4 \%)$ \\
\hline \multicolumn{2}{|l|}{ HCV Genotype, n (\%) } \\
\hline 1a & $94(48)$ \\
\hline $1 b$ & $10(5.1)$ \\
\hline $3 a$ & $75(38.3)$ \\
\hline Mix 1a, 3a & $1(0.5)$ \\
\hline Non-type & $34(16)$ \\
\hline \multicolumn{2}{|l|}{ IL28B alleles, $\%$} \\
\hline $\mathrm{CC}$ & $50.5 \%$ \\
\hline $\mathrm{CT}$ & $43.2 \%$ \\
\hline $\mathrm{TT}$ & $6.3 \%$ \\
\hline \multicolumn{2}{|c|}{ Method of cirrhosis detection } \\
\hline Biopsy, n (\%) & $102(47.4)$ \\
\hline \multicolumn{2}{|l|}{ Fibroscan, n (\%) } \\
\hline $\mathrm{F} 0-\mathrm{F} 2$ & $72(57.2)$ \\
\hline F3 & $27(21.4)$ \\
\hline $\mathrm{F} 4$ & $27(21.4)$ \\
\hline
\end{tabular}

$(63 \%)$ of the patients. In six patients (five patients with $\mathrm{HCV} / \mathrm{HIV}$ co-infection), hemoglobin dropped between 7.5 and $8 \mathrm{mg} / \mathrm{dl}$, which did not respond with the erythropoietin, therefore, forced blood transfusion was carried out for them. In three patients, there was a significant drop in hemoglobin (between 3-5 mg/dl), which the patients had to discontinue their treatment courses.

\section{Treatment Response}

In an intent-to-treat analysis, out of 214 patients, 150 $(70 \%)$ completed their treatment. Overall, 104 patients (48.6\%) reached SVR after 24 and 48 weeks of combined Peg-IFN plus RBV. The virological response in genotypes 1 and 3 was approximately equal. So, out of the 104 patients, $51(49 \%)$ of all genotype 1 and $50(48 \%)$ of all genotype 3 patients reached SVR $(\mathrm{p}<0.05)$. Of the three other patients, one had mix 1a and 3a genotype and the other two patients determined as non-type subjects. In total, $79(76 \%)$ and $25(53 \%)$ of HCV mono-infected and $\mathrm{HCV} / \mathrm{HIV}$ co-infected patients achieved SVR, respectively.

Serious or subjective adverse events due to either peginterferon or ribavirin that discontinued treatment were observed in $30(14 \%)$ patients. In the first group, HCV mono-infected patients, 10 couldn't tolerate the therapy and withdrew their treatments (7 genotype 1, 2 genotype 3 and 1 as non-type). While in the second group, HCV/HIV co-infected patients, the withdrawal reached in 20 patients (9 genotype 1, 7 genotype 3 and 4 as non-type). Another 14 patients $(6.5 \%)$ either voluntarily abandoned treatment or were lost to follow-up. Furthermore, in 20 patients (9 in group 1 and 11 in group 2), HCV infection was spontaneously cleared before treatment beginning. Most of the patients who discontinued their treatments were due to depression, severe flu-like syndrome, anemia and weight loss, particularly in patients with $\mathrm{HCV} / \mathrm{HIV}$ co-infection.

Depending on the stages of liver disease, patients were classified into two groups; F0-F2, absence of fibrosis to moderate fibrosis and F3-F4, with advanced fibrosis or cirrhosis. The detailed virological responses among noncirrhotic (Metavir F0-F2) and cirrhotic (Metavir F3 and F4) patients are shown in Table 2. Out of 126 available data from liver fibrosis, 87 patients completed their treatment. Thirty-nine patients $(31 \%)$ withdrew the treatment (15 patients in group 1 and 24 were in group 2). Only 16 (35\%) of 46 patients who achieved SVR had markers of advanced liver fibrosis, while $21(51 \%)$ of 41 patients with lack of response to treatment had the markers. As shown in Table 2, 46 (53\%) of all 87 patients, achieved treatment response. In both groups, the achievement of SVR occurred in only $17 \%$ of patients with advanced liver fibrosis, while, $34 \%$ of patients in group 1 and $17 \%$ patients in group 2 achieved no treatment response.

Furthermore, Interleukin-28b genotypes (CC, CT, and TT) were obtained for only 95 patients. Interleukin-28b CC genotype were determined in $19(22 \%)$ and 14 (15\%) patients with HCV genotype 1 and 3, respectively. Moreover, CT and TT genotypes were for $20 \%$ and $3 \%$ of patients with HCV genotype 1, respectively. While, $22 \%$ and $2 \%$ of patients with HCV genotype 3 had CT and TT in- 


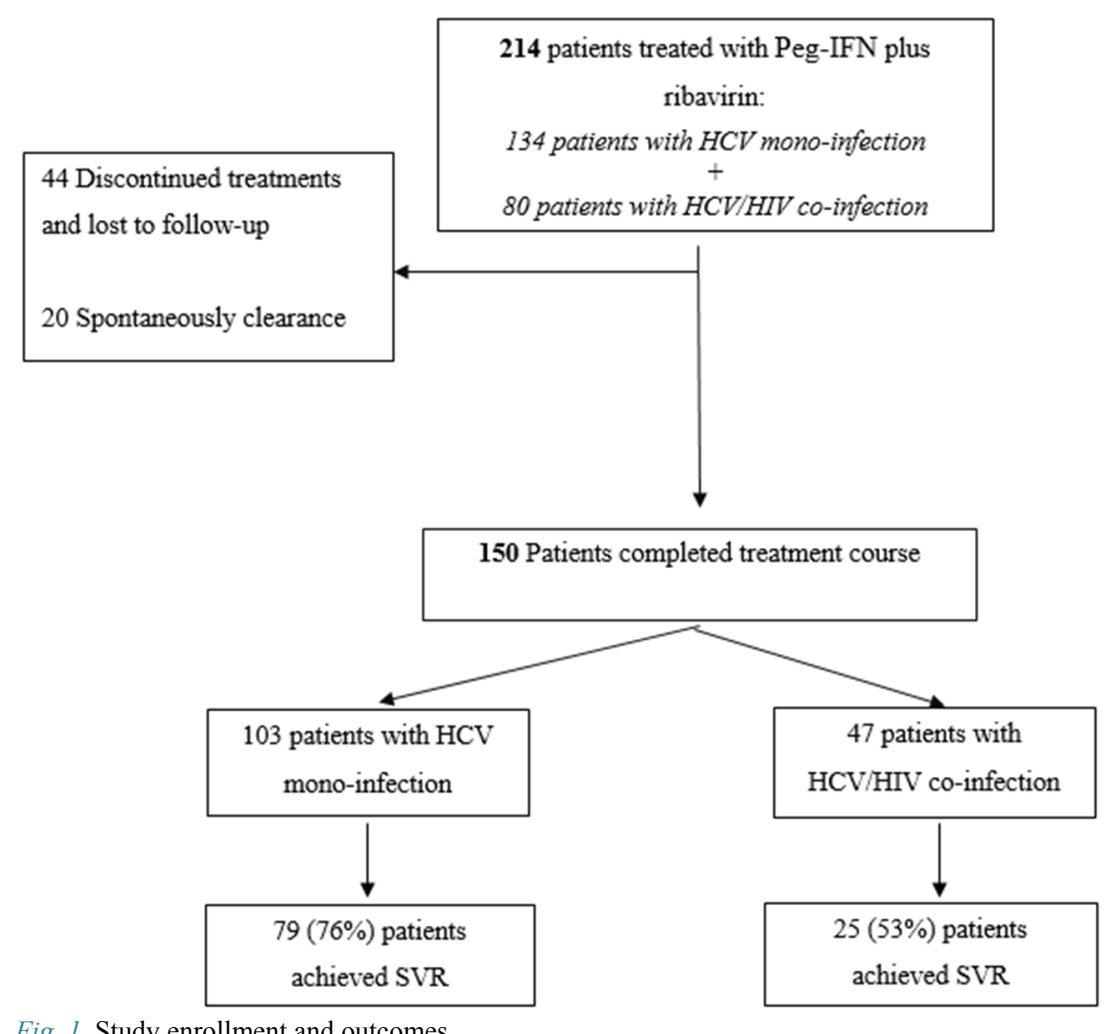

Fig. 1. Study enrollment and outcomes

Table 2. The results of fibrosis using Metavir score by Sustained Virologic Responses and co-infection with human immunodeficiency virus

\begin{tabular}{lcc}
\hline & $\begin{array}{c}\text { Patients with SVR } \\
(\mathrm{n}=46)\end{array}$ & $\begin{array}{c}\text { Patients without SVR } \\
(\mathrm{n}=41)\end{array}$ \\
\hline HCV mono-infection (group 1 patients) & & $5(12 \%)$ \\
F0-F2 & $18(39 \%)$ & $14(34 \%)$ \\
F3-F4 & $8(17.5 \%)$ & $<0.001$ \\
P-value & 0.61 & \\
HCV/HIV co-infection (group 2 patients) & $12(26 \%)$ & $15(37 \%)$ \\
F0-F2 & $8(17.5 \%)$ & $7(17 \%)$ \\
F3-F4 & 0.77 & 0.01 \\
P-value & & \\
\hline
\end{tabular}

terleukin-28b genotypes, as well. There were no significant differences between interleukin-28b alleles, HCV genotypes and virologic responses $(\mathrm{p}=0.15)$.

\section{Discussion}

Hepatitis $\mathrm{C}$ is still the second cause of advanced liver failures in Iran. HCV and HIV may lead to disease progression, including immune system dysfunction and various clinical complications in the setting of co-infection (18). Treatment of HCV-infected individuals with PegIFN and ribavirin can achieve viral clearance and improve histology and prognosis (19-21). In the era, the duration of treatment was tailored according to HCV genotypes, baseline viremia and special patient groups such as HIV coinfection. The study shows the effectiveness of Peg-IFN plus a fixed dose of ribavirin combination therapy among Iranian $\mathrm{HCV}$ mono-infected and $\mathrm{HCV} / \mathrm{HIV}$-co-infected patients.

Therapeutic experience in Iranian $\mathrm{HCV}$-infected patients revealed excellent virological response to the combination of Peg-IFN $\alpha$ and ribavirin either in patients with genotype 1 or 3 . In 2015, Pouresmaeeli et al. (22) showed that $82 \%$ of HCV infected-patients which were treated with Peg-IFN and ribavirin achieved SVR. Another study which was carried out in 2012 among 45 non-cirrhotic Iranian hemophilia patients with chronic HCV, showed that $95.6 \%$ of patients obtained SVR with Peg-IFN $\alpha$ and RBV therapy (23). This result represented that the combination therapy of Peg-IFN- $\alpha$ plus ribavirin among Iranian hemophiliac's patients infected with hepatitis $\mathrm{C}$ is excellent, regardless of genotypes and the patients' conditions.

Sharafi et al. (24) in 2015, showed that the combination therapy with Peg-IFN $\alpha$ and ribavirin among HCV patients with genotype 1 represent a great virological response. They reported that the SVR rate in a highly selected patients group was about $100 \%$. They also verified that the efficacy of a 24-week regimen of Peg-IFN-alfa-2a plus ribavirin was similar to the 48 -week treatment in HCV genotype 1-infected Iranian patients. The results of the present study demonstrated pleasant clinical outcomes with the combination therapy. Approximately $20 \%$ of patients did not respond to the treatment; most of them were patients with advanced liver disease and elderly patients (about $60 \%$ of patients were between the ages of $40-65$ 
years). However, the study by McHutchison et al. (25) showed that the rate of SVR in patients with HCV genotype 1 who were treated with $\mathrm{Peg}-\mathrm{IFNa} / \mathrm{Peg}-\mathrm{IFNb}$ and ribavirin for 24 weeks is lower than Iranian patients from previous documents and also from the current study. Furthermore, they showed that the rates of SVR were significantly different between the two Peginterferon (Peg-IFNa and Peg-IFNb) and ribavirin regimens.

In the setting of HCV/HIV co-infection, very few studies have been ever reported the efficacy of Peg-IFN and RBV combination therapy among Iranian patients. The reports from the study revealed that $53 \%$ of $\mathrm{HCV} / \mathrm{HIV}$ coinfected patients achieved sustained virological response with 48 weeks' treatment course of Peg-IFN plus RBV. This proportion shows a relatively higher rate of virological response to the treatment than the results of other different studies. Torrini et al. (26) showed that only $29 \%$ of HCV genotype 1 patients co-infected with HIV who were treated with Peg-IFN plus RBV for 48 weeks acquired SVR. Furthermore, the other previous studies represented about similar results. Vispo (27), Olmeda (28) and Chung et al. (14) presented that the clearance of HCV RNA at the end of therapy (24-48 weeks) occurred in only 38\%, 30\% and $27 \%$ of HCV genotype 1 patients co-infected with $\mathrm{HIV}$, respectively.

It is obvious that HIV infection has negative impacts on the natural history of chronic $\mathrm{HCV}$ infection; including the decreased rate of $\mathrm{HCV}$ clearance, proliferating $\mathrm{HCV}$ replication, fibrogenesis acceleration, enhancing the risk of advanced liver failures and mortality rates (29). However, it is still unclear why SVR rates are lower in coinfected patients, but finding the involved factors could help to improve available therapeutic options. The crucial point which should be considered is the drug interactions between certain HCV and HIV antiviral drugs. In the setting of co-infection, it is therefore important for the avoidance of zidovudine and didanosine in combination with ribavirin, given the risks of severe anemia, pancreatitis, and lactic acidosis (30-33).

Overall, in the current study, treatment was discontinued in 30 patients because of distinctive adverse events such as psychiatric disorders (depression), weight loss, reduced appetite, and hematologic abnormalities (neutropenia and moderate to severe anemia; toward requiring hospitalization and blood transfusion). Interestingly, contrary to the notion that these problems are more common among co-infected patients rather than in persons with HCV mono-infection, these disorders were observed in almost both groups of patients. However, the most adverse events in the study were lower than those already published, the high rate of treatment discontinuation was considerable $(28,34)$.

Cirrhosis and bridging fibrosis is one of the most important factors that cause a lack of therapeutic response in $\mathrm{HCV}$ infected patients. In some studies, cirrhosis represents as the only baseline predictor of treatment failure. Similar to the results of a study performed by Silva et al. (35), the results of the current study also confirmed that the liver cirrhosis and fibrosis could be a reliable risk factor for non-responders. Moreover, in comparison with
HCV mono-infected patients, HIV co-infected individuals accelerate the progression of advanced liver failures (33).

The present study has some limitations; relatively small sample size, which it's proposed for conduction of multicentric studies to achieve the more appropriate treatment efficacies. Furthermore, the power of the performed analysis is somewhat limited, as liver fibroscan and biopsy were lacked in about half of the patients and also failure for checking HCV RNA at the end of the fourth week of treatment to investigate the rapid virological response.

\section{Conclusion}

In summary, the efficacy of 24-48 week regimens of Peg-IFN-alfa-2a or $2 b$ plus ribavirin represents proper results in our $\mathrm{HCV}$ infected patients. In addition, the present study as the first reports of the efficacy of Peg-IFNalfa plus RBV among Iranian HCV/HIV co-infected patients revealed that the regimen is relatively well tolerated in the patients' group.

However, with the advent of interferon-free treatment regimens, it is hoped that proper responses will be obtained in HCV patients to prevent the adverse effects of interferon-based regimens and reduce the duration of treatment. Various direct-acting antivirals (DAAs) are currently available in the world which possesses magnificent virological responses to $\mathrm{HCV}$ infected patients, even in the specific patient groups such as HCV/HIV coinfection patients (36-38). Although, most drawback was the high cost of these drugs and unaffordability among developing countries. Recently, after the consensus of Iran Hepatitis Scientific Board (IHSB) on the management of Hepatitis C (15), the various new antivirals including Sofosbuvir, Ledipasvir, Daclatasvir and etc. were easily accessible to Iranian HCV infected patients. With the costeffectiveness management of DAAs and easily accessible to Iranian patients, the regimens would be excellent choices for relapsed and naïve patients in the near future.

\section{Acknowledgments}

Authors wish to thank the staff of Liver Disease Center and Iran Hepatitis Network. This work was supported by the Middle East Liver Disease (MELD) Center, Iran Hepatitis Network, Tehran, Iran.

\section{Conflict of Interests}

The authors declare that they have no competing interests.

\section{References}

1. World Health Organization. Global hepatitis report 2017. Geneva: World Health Organization, 2017.

2. Blach S, Zeuzem S, Manns M, Altraif I, Duberg A-S, Muljono DH, et al. Global prevalence and genotype distribution of hepatitis $\mathrm{C}$ virus infection in 2015: a modelling study. Lancet Gastroenterol Hepatol. 2017;2(3):161-76.

3. Mirminachi B, Mohammadi Z, Merat S, Neishabouri A, Sharifi AH, Alavian $\mathrm{SH}$, et al. Update on the prevalence of hepatitis c virus infection among iranian general population: A systematic review and meta-analysis. Hepat Mon. 2017;17(2).

4. Hesamizadeh K, Alavian SM, Shabankareh ANT, Sharafi H. Molecular Tracing of Hepatitis C Virus Genotype 1 Isolates in Iran: A 
NS5B Phylogenetic Analysis with Systematic Review. Hepat Mon. 2016;16(12).

5. Hesamizadeh K, Sharafi H, Rezaee-Zavareh MS, Behnava B, Alavian SM. Next steps toward eradication of hepatitis $C$ in the era of direct acting antivirals. Hepat Mon. 2016;16(4).

6. Hernandez MD, Sherman KE. HIV/HCV coinfection natural history and disease progression, a review of the most recent literature. Curr Opin HIV AIDS. 2011;6(6):478.

7. Bokharaei-Salim F, Keyvani H, Esghaei M, Zare-Karizi S, Dermenaki-Farahani SS, Hesami-Zadeh K, et al. Prevalence of occult hepatitis $\mathrm{C}$ virus infection in the Iranian patients with human immunodeficiency virus infection. J Med Virol. 2016;88(11):1960-6.

8. Hajarizadeh B, Grebely J, McManus H, Estes C, Razavi H, Gray RT, et al. Chronic hepatitis $\mathrm{C}$ burden and care cascade in Australia in the era of interferon-based treatment. J Gastroenterol Hepatol. 2017;32(1):229-36.

9. Platt L, Easterbrook P, Gower E, McDonald B, Sabin K, McGowan $\mathrm{C}$, et al. Prevalence and burden of HCV co-infection in people living with HIV: a global systematic review and meta-analysis. Lancet Infect Dis. 2016;16(7):797-808.

10. Sadeghi F, Bokharaei-Salim F, Salehi-Vaziri M, Monavari SH, Alavian SM, Salimi S, et al. Associations between human TRIM22 gene expression and the response to combination therapy with PegIFN $\alpha-2 \mathrm{a}$ and ribavirin in Iranian patients with chronic hepatitis C. J Med Virol. 2014;86(9):1499-506.

11. Fateh A, Aghasadeghi M, Siadat SD, Vaziri F, Sadeghi F, Fateh R, et al. Comparison of three different methods for detection of IL28 rs12979860 polymorphisms as a predictor of treatment outcome in patients with hepatitis C virus. Osong Public Health Res Perspect. 2016;7(2):83-9.

12. Tavakoli A, Asaadi H, Karbalaie Niya M H, Foroughi-Niya B, Safarnezhad Tameshkel F, Keyvani H. New Treatment Patterns for Hepatitis C Virus Infection. tjpm. 2016; 2 (1) :6-19.

13. Baba M, Pauwels R, Balzarini J, Herdewijn P, De Clercq E, Desmyter J. Ribavirin antagonizes inhibitory effects of pyrimidine 2', 3'-dideoxynucleosides but enhances inhibitory effects of purine 2', 3'dideoxynucleosides on replication of human immunodeficiency virus in vitro. Antimicrob Agents Chemother. 1987;31(10):1613-7.

14. Chung RT, Andersen J, Volberding P, Robbins GK, Liu T, Sherman $\mathrm{KE}$, et al. Peginterferon Alfa-2a plus ribavirin versus interferon alfa2a plus ribavirin for chronic hepatitis $\mathrm{C}$ in HIV-coinfected persons. $\mathrm{N}$ Engl J Med. 2004;351(5):451-9.

15. Alavian SM, Hajarizadeh B, Lankarani KB, Sharafi H, Daryani NE, Merat $\mathrm{S}$, et al. Recommendations for the clinical management of hepatitis C in Iran: a consensus-based national guideline. Hepat Mon. 2016;16(8).

16. Carrat F, Bani-Sadr F, Pol S, Rosenthal E, Lunel-Fabiani F, Benzekri A, et al. Pegylated interferon alfa- $2 \mathrm{~b}$ vs standard interferon alfa-2b, plus ribavirin, for chronic hepatitis C in HIV-infected patients: a randomized controlled trial. Jama. 2004:292(23):2839-48.

17. Lehmann M, Meyer MF, Monazahian M, Tillmann HL, Manns MP, Wedemeyer H. High rate of spontaneous clearance of acute hepatitis C virus genotype 3 infection. J Med Virol. 2004;73(3):387-91.

18. Bastani MN, Bokharaei-Salim F, Keyvani H, Esghaei M, Monavari $\mathrm{SH}$, Ebrahimi M, et al. Prevalence of occult hepatitis $\mathrm{C}$ virus infection in Iranian patients with beta thalassemia major. Arch Virol. 2016;161(7):1899-906.

19. Keyvani H, Fazlalipour M, Monavari SH, Mollaie HR. Hepatitis C virus-proteins, diagnosis, treatment and new approaches for vaccine development. Asian Pac J Cancer Prev. 2012;13(12):5917-35.

20. Bokharaei-Salim F, Keyvani H, Monavari SH, Alavian SM, Fakhim $\mathrm{S}$, Nasseri S. Distribution of hepatitis $\mathrm{C}$ virus genotypes among azerbaijani patients in capital city of iran-tehran. Hepat Mon. 2013;13(9).

21. Fateh A, Aghasadeghi MR, Keyvani H, Mollaie HR, Yari S, Hadizade Tasbiti A, et al. High resolution melting curve assay for detecting rs12979860 IL28B polymorphisms involved in response of Iranian patients to chronic hepatitis $\mathrm{C}$ treatment. Asian Pac J Cancer Prev. 2015;16(5):1873-80.

22. Pouresmaeeli M, Alavian SM, Keshvari M, Salimi S, Mehrnoush L. Efficacy and Tolerability of Peginterferon alpha-2a and Peginterferon alpha-2b in Iranian Patients With Chronic Hepatitis C. Hepat Mon. $2015 ; 15(9)$.

23. Moghaddam MA, Zali MR, Andabili SHA, Derakhshan F, Miri SM, Alavian SM. High rate of virological response to Peginterferon $\alpha-2 \mathrm{a}-$
Ribavirin among non-cirrhotic Iranian hemophilia patients with chronic Hepatitis C. Iran Red Crescent Med J. 2012;14(8):466.

24. Sharafi H, Alavian SM, Keshvari M. Efficacy of 24-week pegylated interferon alpha and ribavirin combination therapy in highly selected patients infected with hepatitis $\mathrm{C}$ virus genotype 1. Hepat Mon. 2015;15(1).

25. McHutchison JG, Lawitz EJ, Shiffman ML, Muir AJ, Galler GW, $\mathrm{McCone} \mathrm{J}$, et al. Peginterferon alfa- $2 \mathrm{~b}$ or alfa-2a with ribavirin for treatment of hepatitis C infection. N Engl J Med. 2009;361(6):580-93.

26. Torriani FJ, Rodriguez-Torres M, Rockstroh JK, Lissen E, Gonzalez-García J, Lazzarin A, et al. Peginterferon Alfa-2a plus ribavirin for chronic hepatitis $\mathrm{C}$ virus infection in HIV-infected patients. N Engl J Med. 2004;351(5):438-50.

27. Vispo E, Barreiro P, Pineda JA, Mira JA, Maida I, MartínCarbonero L, et al. Low response to pegylated interferon plus ribavirin in HIV-infected patients with chronic hepatitis C treated with abacavir. Antivir Ther. 2008;13(3):429.

28. Pérez-Olmeda M, Núñez M, Romero M, González J, Castro A, Arribas JR, et al. Pegylated IFN- $\alpha 2 b$ plus ribavirin as therapy for chronic hepatitis C in HIV-infected patients. Aids. 2003;17(7):10238.

29. Chen JY, Feeney ER, Chung RT. HCV and HIV co-infection: mechanisms and management. Nat Rev Gastroenterol Hepatol. 2014;11(6):362.

30. Bani-Sadr F, Carrat F, Pol S, Hor R, Rosenthal E, Goujard C, et al. Risk factors for symptomatic mitochondrial toxicity in HIV/hepatitis $\mathrm{C}$ virus-coinfected patients during interferon plus ribavirin-based therapy. J Acquir Immune Defic Syndr. 2005;40(1):47-52.

31. Moreno A, Quereda C, Moreno L, Perez-Elías MJ, Muriel A, Casado JL, et al. Short Communication High rate of didanosinerelated mitochondrial toxicity in $\mathrm{HIV} / \mathrm{HCV}$-coinfected patients receiving ribavirin. Antivir Ther. 2004;9:133-8.

32. Henry DH, Slim J, Lamarca A, Bowers P, Leitz G, Group HHCNHS. Natural history of anemia associated with interferon/ribavirin therapy for patients with HIV/HCV coinfection. AIDS Res Hum Retroviruses. 2007;23(1):1-9.

33. Mauss S, Valenti W, DePamphilis J, Duff F, Cupelli L, Passe S, et al. Risk factors for hepatic decompensation in patients with HIV/HCV coinfection and liver cirrhosis during interferon-based therapy. Aids. 2004;18(13):21-5.

34. Moreno L, Quereda C, Moreno A, Perez-Elías MJ, Antela A, Casado JL, et al. Pegylated interferon $\alpha 2 b$ plus ribavirin for the treatment of chronic hepatitis $\mathrm{C}$ in HIV-infected patients. Aids. 2004;18(1):67-73.

35. Silva GF, Villela-Nogueira CA, Brandão Mello CE, Soares EC, Coelho HSM, Abrão Ferreira PR, et al. Peginterferon plus ribavirin and sustained virological response rate in HCV-related advanced fibrosis: a real life study. Braz J Infect Dis. 2014;18(1):48-52.

36. Lawitz E, Mangia A, Wyles D, Rodriguez-Torres M, Hassanein T, Gordon SC, et al. Sofosbuvir for previously untreated chronic hepatitis C infection. N Engl J Med. 2013;368(20):1878-87.

37. Jacobson IM, Gordon SC, Kowdley KV, Yoshida EM, RodriguezTorres M, Sulkowski MS, et al. Sofosbuvir for hepatitis C genotype 2 or 3 in patients without treatment options. $N$ Engl J Med. 2013;368(20):1867-77.

38. Afdhal N, Zeuzem S, Kwo P, Chojkier M, Gitlin N, Puoti M, et al. Ledipasvir and sofosbuvir for untreated HCV genotype 1 infection. $\mathrm{N}$ Engl J Med. 2014;370(20):1889-98. 